\title{
MULTIFUNCTIONAL VILLAGE HALL WITH SUSTAINABLE ARCHITECTURE CONCEPT: AN INTEGRATED LAND USE SYSTEM BY CONSIDERING BUILDING ENERGY EFFICIENCY
}

\author{
Laras Ayu ${ }^{1}$, Ahmad Daris Maimun ${ }^{2}$, Cynthia Permata Dewi ${ }^{3}$ \\ ${ }^{1}$ Department of Civil Engineering, Faculty of Engineering, State University of Malang \\ ${ }^{2}$ Department of Civil Engineering, Faculty of Engineering, State University of Malang \\ ${ }^{3}$ Lecture at Department of Civil Engineering, Faculty of Engineering, State University of \\ Malang \\ e-mail: cynthia.dewi.ft@um.ac.id
}

\begin{abstract}
Environmental pollution is one of the world's problems that is in the spotlight and can be related to all aspects, one of which is social inequality and also economic problems. To solve this problem, the United Nations together with UN member countries created sustainable development goals, which have 17 goals and 169 main targets and are expected to be fully realized by 2030. One of the sustainable development goals that is the focus of attention is goal number 9 on infrastructure, industry, and innovation. Based on these reasons, this paper will discuss sustainable architecture with reviews of various existing studies as one of the efforts to support and fulfill aspects of the Sustainable Development Goals themselves. In the discussion of this paper, the author focuses on the innovation of multifunctional public infrastructure with land use and energy efficiency as a solution to existing social problems. With this research, it is proven that the use of sustainable architecture can be a solution in overcoming the problems of land use and energy efficiency.
\end{abstract}

Keywords: Sustainable Architecture; Building; Environmental Friendly.

\section{Introduction}

Environmental is an important aspect for the survival of human life. Environmental damage and pollution are among the focuses of much-highlighted attention around the world. The increasing use of chemicals is expected to peak in 2030, resulting in ever-increasing contamination of the environment [1]. One of the efforts to stop this is by implementing sustainable development goals initiated by the United Nations and agreed by UN member states to end poverty, social inequality, and protect the environment. Sustainable Development Goals have 17 key objectives and 169 targets that are expected to be achieved by 2030 . The way this program works is by comparing the latest data obtained from each objective focus with existing data [2]. Infrastructure that has a sustainable system is one of the main highlights in the success of this program. This is in line with the aspect of sustainable development goals number 9, namely infrastructure, industry, and innovation.

In addition to the Sustainable Development Goals number 9, this paper is related to the development objectives of programs number $6,7,11$, and 13 that discuss energy efficiency, climate change management, and also the sustainability of terrestrial ecosystems. Lifting from existing environmental problems, and guided by sustainable development goals, then one of the things that can be done is to realize sustainable architecture. Where sustainable architecture is considered to be able to overcome existing infrastructure problems in the sustainable development program goal 
number 9, with modeling that focuses on land use, and building energy effectiveness. The 17 goals of sustainable development goals can be seen in figure 1 .

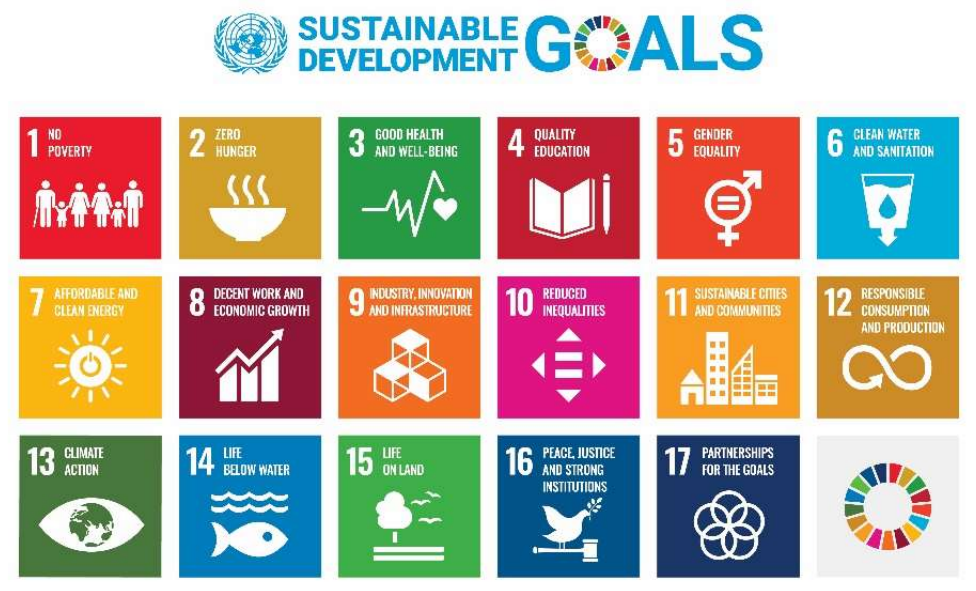

Figure 1. Sustainable Development Goal (United Nation, 2020)

\section{Material and Methods}

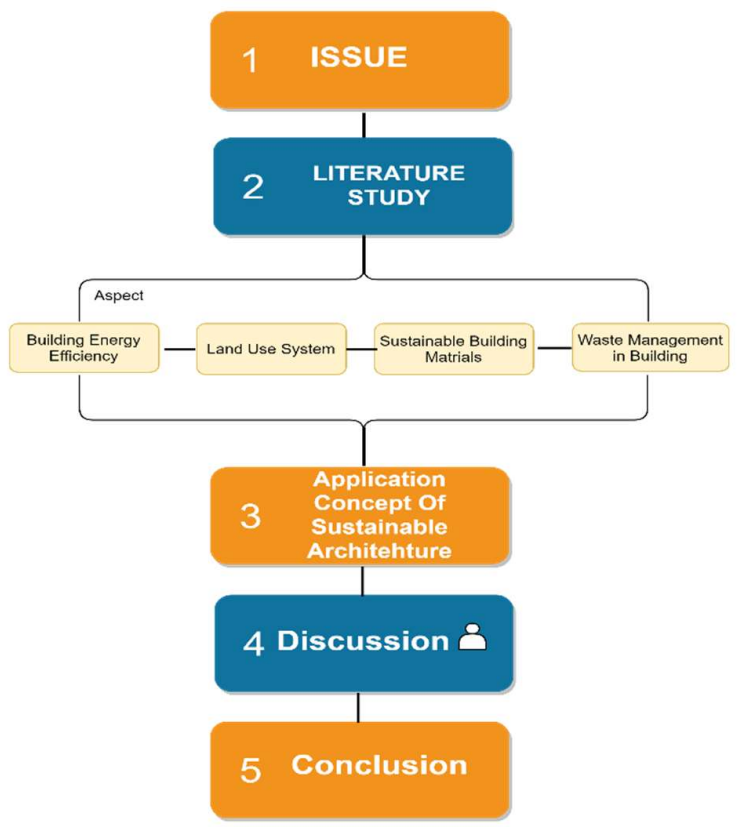

Figure 2. Flowing Chart Research Method Used for This Paper

From the explanation of the table above, to conduct this research, the first is the issue of the existing issues we seek to examine first then for the second is a literature review of the existing issues. This study is taken from international journals, there are about 18 international journals in this study, international journals which is used is published in 2010-2021, the author tries to find and correlate cases that have occurred, especially the author will make a related aspect of the issue, then after finding a correlation from the problems and review of existing literature, the author plans to 
apply it to the surrounding environment, after that the ideas and ideas obtained are discussed first in order to obtain the right study for the last one is to conclude the results of the study related to its realization and especially the development of this research.

\section{Result and Discussion}

\subsection{Basic Concept of Sustainable Architecture}

\section{1.1. Definition}

The design is a very important stage before starting development. The initial design determined by the architect will affect the main energy efficiency that affect the environment. Currently, in line with the sustainable developments goals made by the United Nations involving 194 countries and other economic actors, and has 17 goals with 169 targets expected to be achieved by 2030 [3]. Sustainable developments goals have the goal of solving poverty, inequality, and climate change, so development is running based on the concept of sustainable, initially for Architecture. Sustainable architecture is a building design that maximizes the use of energy, materials, and environmental development, Sustainable architecture can also be interpreted as a way to extend the aging process of existing technology [4]. With the environmental crisis inversely proportional to the lifestyle of the people at this time, force the architect to have innovation in creating buildings that have comfort as well as energy efficiency in them [5].

\subsubsection{Aspect}

Aspects of sustainable architecture, including initial design such as orientation, layout, mass, fenestration, and shading [6]. With the aspects that have been mentioned, the tools to achieve the most advanced aspects have been developed in several studies, such as research on energy efficiency indicators, optimization of design driven by building performance, the influence of design parameters on development that implements energy efficiency, as well as design products that support sustainable building [5] .In this study review discusses building energy efficiency which includes:

1. Building energy efficiency

In this study will discuss the scope of energy efficiency, where the first step of energy saving is by energy consumption efficiency. Efficiency can be done through the use of technologies that require less energy with the same functions and features. This points will include efficiency in lighting and air conditioning resulting in thermal comfort.

2. Land use system

The continued decreased availability of land makes the land use planning system should be maximized its use. Land use planning will affect the sustainability and productivity of the land.

3. Sustainable building materials

In perspective, building materials are directly proportional to the life and performance of buildings and inversely proportional to the impact of environmental damage caused. The use of sustainable materials can improve the impact of environmental damage while prioritizing the performance period of buildings.

4. Waste management in building Waste management in building has optimal waste management coverage and is responsible for reducing the impact of environmental pollution.

\subsection{Building Energy Efficiency}

\subsubsection{Thermal comfort}

Discussions and studies have been conducted to find a result about thermal comfort, including the initial stage of design preparation that includes orientation, geometry, fenestrasi, shading, envelopes, service systems, and renovation strategies. As for other cases that take the study of building energy efficiency problems, the discussion of the burden of heating or cooling energy becomes the most popular topic that has been widely discussed [5]. 
The solution to get the thermal comfort is one of them by applying the façade design for the building. Thermal physics is one method for making design decisions that support thermal comfort, this method produces steps that will help architects to create buildings that have thermal comfort, energy efficiency targets, and passive design testing. [7] .

\subsubsection{Cooling/heating energy}

Architectural concepts that have conformity with sustainable objectives in the environment need to be applied to obtain sustainable buildings. One of the standards for obtaining results from sustainable architecture is by applying efficiency in energy use but still get enough comfort for its residents. Gain comfort in the building, in this case sustainable architecture, it is considered airflow, building layout design, and natural ventilation [8]. Modeling the location of the building also affects the application of cooling / heating energy, among which is raidius distance between buildings, namely $1 \mathrm{H}-2 \mathrm{H}$ from the tap of the target building, where $\mathrm{H}$ is the height of the building [9].

\subsubsection{Lighting design and passive design strategy}

Sources of energy produced from agricultural products are very limited under these conditions, so we should not use energy excessively. Energy sources actually consist of various types, but most of the energy sources currently used are non-renewable energy which will certainly run out such as petroleum. and coal. [10] As the main source of oil will run out at any time. Excessive use of energy will cause damage to the environment. One of the impacts of global warming is caused by excessive use of electricity, to maintain the natural resources that exist on this earth, we must be wiser in the use of existing energy sources in order to create a sustainable life.

Buildings such as buildings, malls, hotels, houses are places where humans gather and carry out activities such as bathing, working, sleeping. In carrying out an activity, humans cannot leave the name of the main energy source when bathing requires electricity, work, infrastructure facilities in which there are human activities must require a large amount of energy, even though the energy used can run out and this is dangerous for the sustainability of life in advance. this earth. basically the use of energy in the building itself is very much, therefore we need a way to save the energy used so that energy from nature does not run out quickly.

Efficient is a way to achieve an optimal goal (fast and precise) and as desired, by minimizing the resources expended. Such as energy, money, time, space that serves to avoid waste. In essence, an effort to achieve maximum goals by minimizing the expenditure of resources used. Building energy efficiency is a business. which is applied to minimize the use of energy, such as electrical energy in buildings to turn on lights used as lighting in buildings.

1. Nowadays, a building is a facility in which there is a human activity, so for activities in the building of course there are supporting facilities and infrastructure for human survival. needed. Mainly to achieve a sustainable building and not leaving the efficiency of the building itself. Buildings are responsible for nearly $40 \%$ of the world's energy consumption, including up to $65 \%$ of electrical energy. In addition, lighting is a major part of building electrical energy consumption.

2. Therefore, research on building efficiency on the object of this multifunctional village hall with the concept of sustainable architecture includes daytime lighting. Regarding the relationship between external and internal daylight levels, this study is a development of previous research on building control systems and has been applied to non-residential buildings, offices and educational buildings. Potential to reduce energy consumption from lighting in non-residential buildings by $28 \%$ for offices and $24 \%$ for educational buildings have been confirmed, but their dependence on certain building parameters has been discussed as well.

3. Building Automation and Control Systems have an important role in increasing the energy efficiency of buildings [11]. Therefore, in recent years one of the main strategies for this sector is to increase energy efficiency by reducing energy used for lighting. Various concepts, approaches, and technologies have been proposed to achieve this goal. Many studies have 
shown that proper lighting control can significantly reduce annual energy consumption. However, this depends on many factors, such as the climatic conditions of the country, the north-south orientation of the building, and the environment, i.e. shade from trees or reflections from neighboring buildings. Many efforts have been made for the energy efficiency of building construction, such as the shape of the building - most of the depth,

4. In recent years, advances in lighting control systems have significantly increased energy savings and visual comfort. In addition, interest in finding new solutions for electric lighting systems and controls has increased due to new architectural design trends as well as the accessibility and lower costs of these new technologies and products. Precise and sophisticated lighting control has become an essential part of lighting systems in modern and retrofitted buildings, both residential and non-residential. For various types of buildings, several control strategies are usually used in modern building designs:

a. Manual switching/dimming

b. Presence/occupancy detection

c. Harvest during the day

d. Constant lighting

This strategy regarding daylight harvesting and constant lighting is very interesting. This strategy can help building occupants work in appropriate lighting conditions and result in additional electrical energy savings. In another study, [12] introduced a new estimation methodology for electrical energy consumption in offices with daylight and artificial lighting controlled by occupancy. Energy savings due to the application of lighting control can be divided into:two aspects: (i) dimming artificial lighting due to daylight penetration and (ii) initial dimming to compensate for overdimensional lighting systems, taking into account the constant illumination.

The concept of energy-efficient architecture optimizes lighting and air conditioning systems, integration between artificial-natural air systems and artificial-natural lighting systems as well as synergies between passive and active methods with energy-efficient materials and instruments. Energy savings through architectural design leads to savings in the use of electrical energy as artificial lighting, air conditioning (air conditioning) and other electrical equipment needed in buildings.

Visual comfort in an office workspace is created if the space user can perform activities well and can feel comfortable in their activities. Activities carried out in the office workspace are closely related to the level of illumination (illumination). In general, designers design lighting based on the level of illumination recommended by SNI 03-6575-2001 on the procedure for designing an artificial lighting system based on the facade of the building and the standard recommended level of illumination for office workspaces is 350 lux. The standard level of illumination is a guide in planning the lighting of the room. In this case, Illumination standard recommendations for office workspaces refer to the values recommended by the CIE (Commission International de I'Eclaire) and IES (Illuminating Engineers Society) which are National and International standards for lighting design (UNEP). Illumination standards are closely related to visual performance research. Several previous researchers researched on visual performance as a reference for determining standard illumination recommendations, especially in office workspaces.

Well-planned buildings, adequate window design and ventilation and other forms of energy savings can reduce energy use significantly. Opportunities to increase energy efficiency are in the construction phase, namely by placing and orienting buildings with attention to nature, such as sunlight, wind, earth shade/shadows of the earth.

Planning is an attempt to utilize existing resources, taking into account their limitations in order to be able to achieve efficient goals. Basically all planning is a way of thinking from idea to form, including workspace planning. Concepts that direct ideas to form are divided into 3 areas. These three fields cannot be seen in parts alone, but must be seen as a whole. These fields are:

1. The environmental field, namely: projects planned with a smaller city environment and environment, site concept, situation, building orientation, human and vehicle roads, waterways, electricity and so on as well as landscaping and noise. 
2. Building sector, namely space forming, space requirements, building construction, economy, building size, building materials, possibility of building expansion and so on

3. The field of function/relationship, namely the relationship between public and private parts, the relationship between spaces, the function of spaces, the comparison of the size of the space, the relationship between the building and the yard, and so on.

Many new buildings ignore the physical aspects of the building and focus more on the visual appearance, resulting in many beautiful buildings but not comfortable to live in. It can be concluded that the design of ventilation, lighting, and acoustics is one way to make our buildings not only beautiful, but also healthy and comfortable. For example: the building as far as possible is in the middle of the land so that all sides are exposed to the wind; ensure ventilation can last 24 hours; avoid complex floor plans; Openings are sought as wide as possible to allow the wind to move in the room, but these openings must be protected from direct sunlight which will heat the room air.

\subsubsection{Influence Factors in Energy-Efficient Building Design}

There are several factors that need to be considered in building design in order to achieve the goal of saving energy use, including:

\subsubsection{Tropical climate influence}

The tropical climate is along the equator to approximately $15 \mathrm{o} N$ and 150 South Latitude. Being in this climate will experience high rainfall, the air temperature generally ranges from $230-320 \mathrm{C}$ with a high humidity level, which is around $75-90 \%$. From an energy point of view, the existence of this relatively high air temperature actually provides an advantage because it does not require energy for space heating as needed by people living in sub-tropical climates. The abundance of sunlight and wind that also characterizes tropical climates becomes a potential which if managed properly will bring great benefits. In this case, the use of energy in buildings is inseparable from efforts to achieve the desired level of comfort in activities. In the context of energy saving, the comfort factor that still needs attention is thermal comfort and visual comfort. Thermal comfort is related to the thermal environment created by air temperature, air flow, air humidity and solar radiation. Meanwhile, visual comfort is related to the amount of light intensity in the space needed to carry out activities properly.

\subsubsection{Effect of environmental quality}

The environment around the building such as the quality of air, soil, and water is one of the factors that influence the choice of design and the success of an energy-efficient building design. Air that has been polluted is no longer reliable as a source of natural ventilation. Likewise, the surface area around the building that reflects the sunlight it receives is the second source of heat and glare after sunlight. For example, pavement and areas of glass in the environment around the building [13].

\subsubsection{The influence of the direction of the building}

The sun's rays will heat the entire area of the building facing it. The East direction as the direction of the sun rises gives an unpleasant heat effect in the range of $09.00-11.00$. While the direction of the West as the direction of the setting sun radiates its maximum heat at $13.00-15.00$. So that in choosing the direction of the building, it is necessary to pay attention to the pattern of movement of the sun and the cardinal directions.

\subsubsection{Influence of Building Area}

The building plan has a considerable influence on the thermal comfort in the building. Complex building plans with many partitions will prevent the flow of fresh air flowing into the building. Besides that, it also limits the use of sunlight as a natural light in the room. 


\subsubsection{Influence of Building Materials}

The heat of the sun affects the indoor temperature in three ways, namely conduction, convection and radiation. Materials that have low conductivity are good insulators, on the other hand, materials with high conductivity are good heat conductors.

\subsubsection{Energy Efficient Building Design Concept}

After knowing the factors that affect the use of energy in buildings, the concept of building design that can minimize energy use is as follows:

\subsubsection{Directions to the building}

By observing the path of the sun, it is known that for the tropics, the east and west directions get the most sunlight. From the sun, what is needed is the brightness and avoids the effects of heat and glare due to solar radiation. Sunlight on buildings consists of $48 \%$ light, $46 \%$ infrared light, and $6 \%$ Ultra Violet light. So by placing the sides of the building which usually has a few openings in the East and West directions, it can reduce the intensity of heat on the face of the building. Thus, facing the front of the building to the north or south will provide more comfort than the front of the building facing east or west

\subsubsection{Building plans and room volume}

Designing the shape of the building plan needs to be based on a function analysis that refers to the actors and activities that will take place in the room. The type of activity will determine the need for the necessary furniture and tools so that it can be seen the amount of space needed so that activities can be carried out freely. The interrelationships between activities, the nature of activities with one another will be the basis for determining the closeness relationship between spaces which in turn creates a floor plan of the building [14]. The more complex the activities that are accommodated in a building, the more caution is needed in managing the space. The shape of the building plan without many partitions in addition to giving the impression of a spacious visual, also enlarges the volume of space so that it slows down the process of heating the indoor air.

\subsubsection{Windows and ventilation}

Windows and ventilation are an integral part of a building, especially with regard to natural lighting and ventilation. For buildings in tropical areas such as Indonesia, the presence of windows in terms of size, number and placement must be planned properly. The window area should be between $15-20 \%$ of the floor area of the room. Windows that are too wide, especially if they are glass windows, can cause glare and space heating effects due to excessive sun exposure. The use of sun shading from wood/iron gratings can reduce excess sunlight.

To improve the quality of natural daylight indoors, the room should receive light from more than one direction, for example by entering light from above by making skylights or light openings on the roof and upper walls. The use of glass block and stained glass as well as creating a void area from the 2nd floor and 1st floor with large enough window openings can make the ground floor brighter. Another way is to adjust the direction of sunlight falling on the building using the reflection method. Meanwhile, so that air can flow naturally, the windows and ventilation are placed on opposite walls (cross position). The difference in pressure inside and outside the building will help the movement of fresh air into the building.

\subsubsection{Building Mass Configuration}

An orderly environmental arrangement between buildings that is sufficient will provide an opportunity for wind to enter and leave properly, the scale of the building must be in accordance with the KDB (basic building coefficient) and KDH (Green Basic Coefficient) which ranges from 40-70 percent of built space compared to 30-60 percent of open space green. 


\subsection{Land Use System}

Land degradation, at this time is quite one of the problems that should be considered. From year to year, the decrease in the level of land availability is increasingly alarming. Land degradation is currently a global problem and is one of the goals of sustainable development goals [15]. The dual land use system allows for high land use efficiency and becomes increasingly relevant amid land scarcity [16]. Because of land degradation, land maximization is one of the things that can be used for solutions. In this case, the concept of buildings that have land optimization can also be done. Sustainable architecture, applying minimalist land use to be able to produce space and also maximum function, one of the highlights is the maximization of energy.

\subsection{Sustainable Building Materials}

The phenomenon of global warming caused by the effects of greenhouse gases on Earth is believed by researchers that one of the causes is development activities. An idea that is considered to have the potential to reduce global warming by applying the concept of sustainable development. This concept contains three main pillars that are interrelated and mutually supportive, namely economic development, social development and environmental conservation. In Law no. 23 of 1997, sustainable development is defined as a conscious and planned effort, which integrates the environment, including resources, into the development process to ensure the ability, welfare, and quality of life of present and future generations.

Sustainable construction is defined as construction that pays attention to sustainability aspects, namely the use of natural resources that pays attention to the carrying capacity of the environment to avoid environmental quality degradation. Many factors are the cause, one of which is inefficiency in the construction process. Related to the limited quantity of natural resources, it is necessary to make efforts to save natural resources and if necessary use used materials that are still suitable for use without reducing aspects of the strength of the building. Until now there is not much information about the potential of used materials as materials in the construction of construction projects.

The concept of sustainability has been applied in many fields, one of which is the construction sector. The construction sector has a significant impact on the environment. Globally, the construction sector consumes $50 \%$ of natural resources, $40 \%$ of energy and $16 \%$ of water. Considering the large consumption of natural resources in construction activities, it is necessary to have good planning in their management in order to pay attention to the sustainability aspects. Buildings use nearly $16 \%$ of fresh water and $25 \%$ of their timber harvest on a universal scale. Other than that, Buildings produce $25 \%$ of all ozone depleting chlorofluorocarbons released by the process of producing building materials and building air conditioners [17]. Thus, buildings have a negative impact on their life cycle on the environment and human health. In fact, a worldwide dilemma is how to deal with the ongoing passive effects that construction activities cause on the environment throughout the project life cycle. Globalization leads to depletion of resources and environmental degradation to meet demands. So, sustainable building construction was found to be the best key to avoid resource depletion. Thus, the selection of sustainable building materials becomes more important which is a difficult process [18]. Sustainable buildings or green buildings are defined as high quality buildings they last longer and cost less to operate and maintain. The main advantage of sustainable buildings is to protect human health and minimize negative impacts on the environment [19]. They are the optimal solution to reduce resource consumption, minimize environmental damage, reduce waste, reduce energy loss and increase the use of renewable energy. According to the international residential construction community green building is considered as a long term strategy to reduce Life Cycle Cost and passive environmental effects throughout its life cycle. The main advantage of sustainable buildings is to protect human health and minimize negative impacts on the environment. They are the optimal solution to reduce resource consumption, minimize environmental damage, reduce waste, reduce energy loss and increase the use of renewable energy [20] .

Building materials are one of the most important aspects in project quality estimation. They have many negative effects during extraction, manufacture, construction, maintenance, disposal and 
recycling .The designers must decide which materials to use for consideration in the early stages of the project. Therefore, the principle of sustainability is very important in choosing building materials.

\subsubsection{Sustainable building materials selection modeling}

System dynamics (SD) was used to take into account the inner relationship among the parameters that influence the selection of SBM. SD is a mathematical technique for modeling, framing and examining complex problems [Tripathi and Pandit]. The circular loop of information feedback is a tool for understanding the structure of complex systems. The systems dynamics approach provides an excellent tool for simplifying reality and estimating the system's ability to adapt to change. It helps in solving the simultaneity problem by updating all parameters in small time increments with negative and positive feedback and time delays compiling interactions and controls.

Table 1. Parameters that influence the selection of sustainable building materials.

\begin{tabular}{ll}
\hline No & \multicolumn{1}{c}{ Parameter } \\
\hline 1 & Carbon Emission \\
2 & Elimination of hazardous and toxic materials \\
3 & Material waste generator \\
4 & Energy embodied in materials \\
5 & Recycled materials \\
6 & Recyclable waste \\
7 & Raw material extraction method \\
8 & Health and safety \\
9 & Thermal Insulation \\
10 & Fire Resistance, \\
\hline
\end{tabular}

After getting the parameters that must be achieved in order to get sustainable building materials, then it can be classified on materials and building materials in outline as in the next stage, namely the application of the model.

\subsubsection{Model application}

In this section, the developed model is applied to evaluate different building materials as a step towards selecting the most SBM. The SD model has the ability to evaluate the performance of building materials from many sides where they are interrelated and change over time. Building materials are evaluated according to the amount of their waste, the amount of waste delivered to the landfill, amount of waste that can be recycled, life cycle costs and health and safety indices.

Indeed, it is not easy to consider all the proposed sides during the selection because each project has its characteristics, so it is necessary to determine the project objectives. Depending on the goal, the purpose of the SD model can be determined. In the current application, this model is based on evaluating and comparing the performance of building materials. First, this model is applied to evaluate the performance of common building materials, for example, wood, concrete and steel. These materials are widely used in the construction sector. It is important to evaluate and appreciate their environmental impact. Second, a model is applied to choose between building materials and their alternatives. Polystyrene foam and cellulose were compared as thermal insulation materials. Ceramics and linoleum are compared as flooring materials.

\subsubsection{Material evaluation}

The most widely used building materials are wood, concrete and steel. It is necessary to evaluate their performance during project construction. These materials are used in large quantities in any construction. It is known that these materials are very important in every 
building. The main purpose of evaluating the performance of these materials is to help the designer to be fully aware of them during the selection process. By doing so they can look for alternatives or reduce the amount used if possible.

\subsection{Waste Management in Building}

Construction project development will always produce a large amount of waste, so if it is not managed properly, the construction waste can become a serious problem for the environment. The waste management model is basically carried out through the stages of avoid, reduce, recycle and disposal. Construction waste is defined as unused material resulting from the construction process, repair or alteration or any goods produced from the process or an accident that cannot be directly used at the place without any further treatment. Construction waste material is generated in every construction project, be it a construction project or a demolition project (construction and domination). Waste originating from demolition or demolition of buildings is classified as domestic waste, while waste originating from remodelling, repairs, be it houses or commercial buildings, is classified as construction waste. The composition of construction waste is in the form of stone, concrete, bricks, plaster, worthless goods, roofing materials, plumbing materials, electrical installation materials. Source and Composition of Waste from construction projects. Waste in the implementation of construction projects is basically undesirable to occur. Construction waste arises for several reasons, namely:

1. There is a difference between the size of the material purchased and the size of the material needed

2. Contractor incompetence

3. Lack of knowledge in carrying out the work so that it affects the work methods used.

About $1-10 \%$ of the material used in construction works will become construction waste and generally $50-80 \%$ is waste that can be reused. In general, construction waste can be categorized into 4 types:

1. Natural waste is waste that cannot be avoided in its formation, for example, cutting wood for joining or paint sticking to the can when painting.

2. Direct Waste, is waste that occurs at every stage of development. Usually this waste is formed during storage, when the material is moved to the workplace, or during the development process itself.

3. Indirect waste occurs as a result of purchasing materials that are not in accordance with market prices. For example, purchasing materials that are more expensive than the market price

4. Consequential waste is waste caused by work errors, as a consequence is the occurrence of material wastage in replacing or adding material capacity to replace work that is not in accordance with work specifications.

The waste treatment hierarchy based on Chun-li Peng, Domenic E. Scorpio and Charles Kibert in Strategies for Successful Construction and Demolition Waste Recycling Operations (1995) is:

1. Reduction is the best and most efficient way to minimize the waste generated. Indirectly, hazardous and toxic and hazardous substances will be reduced so that the costs of managing toxic and hazardous waste will be reduced.

2. Reuse is the transfer of the use of an item to another use. It is a good way after reduction, because of the minimization of the implementation process and the energy used in its implementation.

3. Recycling is the reprocessing of old materials into new materials. This is a method that does not produce new goods but is also economically profitable, because the goods can be resold.

4. Landfilling, is the last option that can be done in waste management, namely disposal to the final shelter. Landfilling is carried out only when other alternatives cannot be carried out. 
In residential, housing and building projects, the most dominant type of construction waste is wood waste and demolition debris, where the percentage reaches $20-30 \%$ of the total waste. In industrial and heavy building projects, the most dominant construction waste besides wood waste and demolition debris is waste from excavated soil. This happens because in industrial and heavy building projects there is a large amount of excavation, and if it is not used it will become waste. In the waste management activities carried out, then:

1. For activities that are directly related to waste, activities for collecting waste, cleaning the workplace are the activities that are most often carried out, while activities for storing waste that can be reused are only occasionally. This is due to the limited project space and short implementation time, so that the time and place to further manage the waste has not become a priority.

2. For waste disposal, it is most often done by renting a truck to quickly dispose of the waste or give it to those in need. This of course will not benefit you even have to pay for the disposal.

3. In the aspect of waste management, the effort to manage waste that occurs has not been carried out routinely, a plan has been made because it is part of the work agreement with the owner, but in the implementation stage it has not been carried out even for subcontractors.

\section{Conclusions}

The conclusion of our paper is how we carry out the efforts made to save the earth from global warming. Because as explained above the building is one of the contributors to the effect that causes the depletion of the ozone layer. Therefore, an efficient sustainable building concept is needed. The concept of sustainability has been applied in many fields, one of which is the construction sector. The construction sector has a significant impact on the environment. Globally, the construction sector consumes $50 \%$ of natural resources, $40 \%$ of energy and $16 \%$ of water. Given the large consumption of natural resources in construction activities, it is necessary to have good planning in their management by taking into account aspects of supporting sustainable development such as:

Building Energy Efficient: Indonesia is a country that has a tropical climate. The tropical climate is along the equator to approximately $15 \mathrm{LU}$ and $15 \mathrm{LS}$. Being in this climate will experience high rainfall, the air temperature generally ranges from $23-32 \mathrm{C}$ with a high level of humidity, which is around $75-90 \%$. From an energy point of view, the existence of this relatively high air temperature actually provides an advantage because it does not require energy for space heating as needed by people living in sub-tropical climates. Even in certain situations and air conditions when the air temperature can no longer be tolerated, an air conditioning device that consumes energy will be needed. The abundance of sunlight and wind which is also a characteristic of tropical climates becomes a potential which if managed properly will bring great benefits. In this case, the use of energy in buildings is inseparable from efforts to achieve the desired level of comfort in activities. So related to energy efficient buildings in Indonesia, it is very appropriate to be supported by good weather and climate conditions, I think this aspect can be done in this development.

Land Use System: the use and arrangement of building land is very important for the concept of sustainable building architecture because in addition to the building itself, the building must also provide benefits to its occupants. An orderly environmental arrangement with sufficient distance between buildings will provide an opportunity for the wind to circulate properly. The application of good land use in my opinion can be done in Indonesia, you must pay attention to green space, KDB and existing regulations in constructing buildings, with rationalization when you want to build and plan a building this should think long term, because this building will continue to be inhabited by successors For us, we need a good design and arrangement, which ones can be exposed to sunlight, which ones don't have noise, this must be considered carefully.

Sustainable Building Materials: Indonesia is famous for its abundant natural resources, it is not impossible that in the future Indonesia will be able to compete with foreign countries in the field of 
construction, especially students as agents of change are needed here in an effort to improve existing quality.

Waste Management In Building: In a building/house in which there are human activities, it will certainly cause an interaction between one and another, it does not stop there, of course there are activities that cause waste such as washing, bathing, of course in this case there are still many found in Indonesia a disposal system that is not in accordance with procedures, this results in environmental pollution, but in an effort to improve the earth and care for the environment I think with the sophistication of today's technology, the awareness of Indonesian citizens in preparing a house/building disposal system will be very easy because with the sophistication of existing technology, we are required to be ready, for the sake of a better future for our country.

For that we as humans who care about the environment must think about the preservation of nature, because when we care about nature, then nature will care about us, in the future I hope there will be a realization of the research that has been done so that many developments occur in order to create materials efficient building.

\section{Acknowledgements}

This paper was supported by State University of Malang.

\section{References}

[1] N. R. Eugenio, L. Montanarella, M. McLaughlin, and R. Vargas, "Environment Pollution journal - Special Issue: Global status of soil pollution,” Environ. Pollut., p. 115231, 2020, doi: 10.1016/j.envpol.2020.115231.

[2] G. Halkos and E. C. Gkampoura, "Where do we stand on the 17 Sustainable Development Goals? An overview on progress," Econ. Anal. Policy, vol. 70, pp. 94-122, 2021, doi: 10.1016/j.eap.2021.02.001.

[3] R. A. Rae, "Cemeteries as public urban green space: Management, funding and form," Urban For. Urban Green., vol. 61, no. August 2020, p. 127078, 2021, doi: 10.1016/j.ufug.2021.127078.

[4] H. N. Zebari and R. K. Ibrahim, "Methods \& Strategies for Sustainable Architecture in Kurdistan Region, Iraq," Procedia Environ. Sci., vol. 34, pp. 202-211, 2016, doi: 10.1016/j.proenv.2016.04.019.

[5] C. Wang, S. Lu, H. Chen, Z. Li, and B. Lin, "Effectiveness of one-click feedback of building energy efficiency in supporting early-stage architecture design: An experimental study," Build. Environ., vol. 196, no. February, 2021, doi: 10.1016/j.buildenv.2021.107780.

[6] Z. Tian, X. Zhang, X. Jin, X. Zhou, B. Si, and X. Shi, "Towards adoption of building energy simulation and optimization for passive building design: A survey and a review," Energy Build., vol. 158, pp. 1306-1316, 2018, doi: 10.1016/j.enbuild.2017.11.022.

[7] N. A. Azmi and M. Z. Kandar, "Factors contributing in the design of environmentally sustainable mosques," J. Build. Eng., vol. 23, no. August 2018, pp. 27-37, 2019, doi: 10.1016/j.jobe.2019.01.024.

[8] S. Zheng, Y. Wang, Z. (John) Zhai, Y. Xue, and L. Duanmu, "Characteristics of wind flow around a target building with different surrounding building layers predicted by CFD simulation," Build. Environ., vol. 201, no. May, 2021, doi: 10.1016/j.buildenv.2021.107962.

[9] Y. Tominaga et al., "AIJ guidelines for practical applications of CFD to pedestrian wind environment around buildings," J. Wind Eng. Ind. Aerodyn., vol. 96, no. 10-11, pp. 17491761, 2008, doi: 10.1016/j.jweia.2008.02.058.

[10] N. Jamala, "ANALISIS PENCAHAYAAN BANGUNAN HEMAT ENERGI (Studi Kasus : Gedung Wisma Kalla di Makassar)," J. Penelit. dan Karya Ilm. Arsit. Usakti, vol. 15, no. 2, pp. 62-70, 2015, doi: 10.25105/agora.v15i2.2028.

[11] E. Shamsaei, F. B. de Souza, X. Yao, E. Benhelal, A. Akbari, and W. Duan, "Graphene-based nanosheets for stronger and more durable concrete: A review," Constr. Build. Mater., vol. 183, pp. 642-660, 2018, doi: 10.1016/j.conbuildmat.2018.06.201. 
[12] A. Azwanda, S. Samsunan, and H. D. Rangga, "Pengaruh Subtitusi Bahan Anorganik Plastik Terhadap Kuat Tekan Beton Normal," J. Tek. Sipil, vol. 3, no. 4, pp. 52-63, 2017.

[13] R. S. Rivai and I. S. Anugrah, "Konsep dan Implementasi Pembangunan Pertanian Berkelanjutan di Indonesia," Forum Penelit. Agro Ekon., vol. 29, no. 1, p. 13, 2016, doi: 10.21082/fae.v29n1.2011.13-25.

[14] H. Du, H. J. Gao, and S. D. Pang, "Improvement in concrete resistance against water and chloride ingress by adding graphene nanoplatelet," Cem. Concr. Res., vol. 83, pp. 114-123, 2016, doi: 10.1016/j.cemconres.2016.02.005.

[15] K. Schulze, Ž. Malek, and P. H. Verburg, "How will land degradation neutrality change future land system patterns? A scenario simulation study," Environ. Sci. Policy, vol. 124, no. February, pp. 254-266, 2021, doi: 10.1016/j.envsci.2021.06.024.

[16] A. Feuerbacher et al., "An analytical framework to estimate the economics and adoption potential of dual land-use systems: The case of agrivoltaics," Agric. Syst., vol. 192, no. June, 2021, doi: 10.1016/j.agsy.2021.103193.

[17] M. Marzouk and A. Othman, "Modeling the performance of sustainable sanitation systems using building information modeling," J. Clean. Prod., vol. 141, pp. 1400-1410, 2017, doi: 10.1016/j.jclepro.2016.09.226.

[18] P. T. H. Ha, "A concept for energy-efficient high-rise buildings in Hanoi and a calculation method for building energy efficiency factor," Procedia Eng., vol. 142, pp. 154-160, 2016, doi: 10.1016/j.proeng.2016.02.026.

[19] M. Zhang, Y. Lian, H. Zhao, and C. Xia-Bauer, "Unlocking green financing for building energy retrofit: A survey in the western China," Energy Strateg. Rev., vol. 30, p. 100520, 2020, doi: 10.1016/j.esr.2020.100520.

[20] J. K. W. Wong and J. Zhou, "Enhancing environmental sustainability over building life cycles through green BIM: A review," Autom. Constr., vol. 57, pp. 156-165, 2015, doi: 10.1016/j.autcon.2015.06.003. 